The

Connecticut

\title{
Greenhouse
}

Agricultural

\section{Tomato Cultivar}

Experiment

Trials in

Station,

New Haven

Connecticut

1999-2002

Bulletin 990

BY MARTIN P.N. GENT

December 2003 


\section{SUMMARY}

Vegetable growers produce tomatoes in greenhouses to capitalize on the demand by consumers for fresh and native vegetables with improved taste and nutritive qualities. Hydroponics is a production technique that appeals to consumers, in part because vegetables can be grown without use of pesticides. This report compares the yield characteristics for 21 cultivars of greenhouse tomato grown using rockwool, an inert root medium used in hydroponics.

Total yield from a 3 -month picking varied from 10 to 16 pounds per plant. Cabernet, an openpollinated beefsteak cultivar, had the highest total yield, but four other beefsteak cultivars had yields indistinguishable from Cabernet. Fruit size varied from 7.5 ounces for Nicklow 102, down to about 3 ounces for Cronos and Dynamo. Quest, a beefsteak type, had the best yield of marketable fruit, nearly 10 pounds per plant, followed by Buffalo, Match, Mississippi and Trust. All these were beefsteak cultivars with a uniform ripening characteristic. Most cultivars had a marketable yield in the range of 6 to 8 pounds per plant. Cronos and Tradiro were the only cluster types with similar marketable yields. Cracks tended to develop in the skin of large fruit. Although Cabernet, Jet Star, and Nicklow 102 had higher yields and larger fruit than Quest, their marketable yield was lowered by a substantial number of fruit with cracked skin. Quest and Mississippi did not follow this trend, in that they had large fruit but a relatively low fraction with cracked skin. Cronos and Tradiro had high marketable yields because they did not suffer from green shoulder, or fruit too small to be marketable, defects that were common in the other cluster types in this trial. In general, the ranking among cultivars for total yield, market yield, and fruit size remained the same from year to year in this 4-year trial.

The best yields and most constant rate of production were achieved when seeds were germinated in late January and transplanted into the greenhouse in early March. Tomatoes commenced to ripen in late May. The fruit ripened only slightly earlier when planting was a month earlier, and later planting reduced yield and fruit quality. Some aspects of rock-wool culture differed from that for plants grown in soil or peat-lite mix. Rock-wool should never be allowed to run dry, because the concentration of nutrients in the remaining solution increases to the point that it is deleterious to fruit size and quality. The rock-wool root medium tends towards a basic $\mathrm{pH}$ when plants are fed nitrate nitrogen, because rock-wool has little buffering capacity. Thus, acid must be added to the nutrient solution to maintain a pH 5.6 to 6.6. With these precautions, the yields of high-quality tomatoes using rock wool can equal or exceed that for plants grown in soil or other growing media. 


\title{
Greenhouse Tomato Cultivar Trials in Connecticut 1999-2002
}

\author{
By Martin Gent
}

\section{INTRODUCTION}

Fresh and native vegetables are in demand by consumers for their improved taste and nutritive qualities. They command high prices out of season. To capitalize on this demand, many vegetable growers in the northeast US sell at retail to the large population that resides near their farms. They use plastic shelters or greenhouses to promote earliness, extend the duration of harvest and allow production of frost sensitive vegetables outside the field-growing season. Connecticut was a major producer of greenhouse tomatoes until the 1960s (Wittwer and Honma 1979), when the energy requirements of a heated greenhouse and the rising price of fuel almost eliminated greenhouse vegetable production in the northeast. However, there has been a resurgence of greenhouse tomato production over the last 20 years, related to an increase in direct retail to consumers from farm stands. Currently, more than 40 farmers grow out-of-season tomatoes in greenhouses in Connecticut. Peppers, cucumber, lettuce, and edible herbs are also produced in greenhouses on a small scale.

Modern greenhouse production methods differ from those of 40 years ago. In the 1960s, plants were typically grown in glass-covered greenhouses. These heavy-duty structures offered more shade, and sidewall plus ridge vents offered more ventilation, than the current generation of plastic covered greenhouses. In the current day, plants are typically grown in single-span hoophouses covered with a double layer of polyethylene film. This design requires little superstructure, and the film is cheap enough to be replaced every 2 to 3 years. Fanforced ventilation is often used along thie length of the house. Thus, there is greater light penetration and worse air exchange in present-day polyethylene-covered greenhouses than in glass greenhouse designs used in the past. When older cultivars were developed, plants were typically grown in soil. Cultivars that are most popular today were developed when a peat-vermiculite mix was a standard substrate for greenhouse vegetable production. Most recent releases were developed in Holland, where plants are grown in nutrient solution using rock-wool substrate. These differences in substrate and environment change the nutrient requirements and the response of different cultivars to cultural conditions.

There are a great number of varieties or cultivars of greenhouse tomato available, and new ones are developed continuously. Cultivars bred for greenhouse conditions yield more than those bred for field production (Anderson 1996). Beefsteak types generally yield more than cluster types (Hochmuth et al 2000). The latter generally have smaller fruit of 3 to $4 \mathrm{oz}$ compared to 6 to $8 \mathrm{oz}$ for beefsteak types. The cultivar 'Trust' is a beefsteak type that is recommended in nearly all production guides. It is the most widely used cultivar for greenhouse production in the USA. Some older cultivars, such as 'Tropic' and 'Jumbo' are still recommended in the south (Dickerson 1998, Koske et al 1998). However, the newest releases grown under modern cultural conditions yield more than 'Trust' (Rorabaugh and Jensen 2001). There are a wide variety of other cultivars suggested in various production guides (Precheur 2003, Oregon 2002, and Snyder 2001).

There is a variety of general information available concerning commercial greenhouse tomato production in the form of books (Blom et al 1989, Wittwer and Honma 1979), or vegetable production guides that are now often found as WEB pages (Dickerson 1998, Snyder 2001, Oregon 2002). There is also information specific to production using hydroponics in book form (Resh 1995) and as WEB pages (Ells et al 1991, Jensen and Rorabaugh 2001). For information specific to greenhouse construction and operation see Aldrich and Bartok 1994, and Hanan et al 1979. Another useful resource on the internet is a list of references to other publications that deal with various aspects of greenhouse production (Donnell 2001, Peet 1999).

Because both cultural methods and available cultivars have changed substantially in recent years, it is not clear which cultivars of tomato are most appropriate for greenhouse production in Connecticut, or for use in hydroponics. This report presents data for 21 cultivars of tomato developed for greenhouse production. These cultivars were grown in one or more years of a 4-year trial to evaluate their yield characteristics and suitability for tomato production. The tomato plants were grown in rock-wool, a medium that only provides support and aeration of the roots. All nutrients must be supplied in the irrigation water. This method of hydroponics is popular for commercial greenhouse vegetable production in Europe. No previous trials in the northeast US have compared greenhouse tomato cultivars grown in rockwool.

\section{MATERIALS AND METHODS}

\section{Growth conditions and culture}

The experiment was conducted in the four years from 1999 through 2002 in greenhouses at Lockwood 
Farm, Hamden, CT (Lat. 42 N Long. 73 W). Each greenhouse was a $14 \times 56 \times 8$ feet high $(4.4 \times 17 \times 2.5 \mathrm{~m})$ frame structure consisting of 1.25 in steel hoops set in the ground at 4-ft intervals. This frame was covered with an inflated double-wall 4-mil clear-polyethylene cover (Type $703 X$ L, Huntsman Packaging, Salt Lake City UT). The long axis was oriented east-west. A forced-air heater fueled with propane and set in the northwest corner of each house provided a source of heat. A 16-in fan set in the opposite corner provided horizontal air circulation to stabilize temperature throughout each house. A $7 \times 8 \mathrm{ft}$ $(2.1 \times 2.4 \mathrm{~m})$ door at each end of the greenhouses was opened and closed on temperature set points to cool the house using natural ventilation.

Climate control set points changed over the year. In late winter and early spring, minimum temperatures were $70 \mathrm{~F}(21 \mathrm{C})$, and houses were ventilated in the temperature range from 78 to $84 \mathrm{~F}$ ( 24 to $28 \mathrm{C}$ ). Later in the spring, minimum temperatures were lowered to $60 \mathrm{~F}$ (15C) and houses were ventilated at 72 to $78 \mathrm{~F}$ ( 20 to 24C). Beginning in June, high sunlight intensity and warm outdoor temperatures often results in maximum temperatures of $95 \mathrm{~F}(36 \mathrm{C})$ within the greenhouses.

Around mid-June, no supplemental heat was used, and the end doors were removed to maximize ventilation. In 2000 and 2001, aluminized shade cloth was applied at this time to reduce solar radiation load by $30 \%$. The shade cloth was stretched across the top of the greenhouse. A black woven shade cloth was applied to the south side of each greenhouse to the height of $6 \mathrm{ft}$, to shade the south row and mimic the effect of a border tow of plants.

Seeds were placed $1 / 4$ in. deep in peat-lite mix in 1 in. diameter pots and germinated in a growth room operated at $72 \mathrm{~F}$ with a 12 -hour photoperiod. Plants were thinned to a uniform size about one week after emergence. After 4 to 6 weeks, plants were moved to a production greenhouse. The root ball was transplanted into the center hole of a 4-in. rock-wool cube. Cubes were set in styrofoam trays and watered from above with nutrient solution at three to four day intervals. After a further 2 to 3 weeks, when a substantial number of roots had emerged from the bottom of the rock-wool cubes, the plants were set at their final spacing on rock-wool slabs. The root medium was rock wool slabs $36 \times 6 \times 3$ in. high $(90 \times 15 \times 7.5 \mathrm{~cm})$ covered with white polyethylene film (Grodan, Denmark supplied by Agrodynamics, Coppell TX). These slabs were leveled and set on pieces of 1-in. thick polystyrene foam insulation to form a continuous row along the length of the house. The slabs were saturated with nutrient solution, and then the plastic wrapping was cut across the bottom at both ends of the slab. Two 4-in. squares of plastic covering were removed from the top surface and two plants in rock-wool cubes were placed on top of each pre-watered rock-wool slab.
Both the transplanted cubes and slabs were wrapped with white-on-black polyethylene film to form a continuous trough that was drained at one end.

As the plants developed, they were pruned to maintain a single stem. The stem was supported by a string twisted around the stem and hung from a support wire at a height of $7 \mathrm{ft}(2.1 \mathrm{~m})$ that ran along the length of each row. At weekly intervals, suckers were removed when they were 3 to 6 in. long ( 7 to $15 \mathrm{~cm}$ ), and the stem was lowered using the support string, to keep the stem apex at below or the height of the support wire. Older leaves were removed if they lay on the floor of the greenhouse after the stem was lowered. Neither vibration nor other methods were used to enhance pollination of the flowers. When the developing fruit reached pea-size, they were pruned to 4 or 5 per truss. The fruits were harvested when they ripened, when more than $75 \%$ of the surface was red. The harvests were done at 4- to 5-day intervals over a period of about 90 days. The total yield and number, market yield and number, fruit size, and nature of defects of the fruit were recorded for each sub-plot at each picking. Marketable fruit had no cracks, rough skin, green shoulder, blossom end rot, irregular shape such as cat facing, or insect or other damage, and was at least two ounces in size.

Insect pests were controlled by beneficials (Applied Bionomics, Sidney B.C. distributed by IPM Labs, Locke NY). Lacewing (Chrysoperla rufilabris) was released in at a rate of 0.3 per square foot $\left(3.2\right.$ per $\left.\mathrm{m}^{2}\right)$ to control aphids, and a predatory mite (Neoseiulus cucumeris) was released at a rate of 3 per square foot to control two-spotted spider mite. These releases were begun in mid-May and repeated three times at 2-week intervals. Tomato hornworm was an occasional problem. They were controlled by handpicking the worms when they became large enough to detect. No insecticides or fungicides were applied.

\section{Fertilization}

Plants were watered at least once a day, or more often depending on sunlight, once they were transplanted on rock-wool slabs. Each plant was supplied with nutrient solution controlled by a 2-gal per hour drip emitter with a positive pressure cut-off (Netafim, Haifa, Israel distributed by W.H. Milkowski, Stafford Springs CT). Initially, the duration of each watering was two minutes, corresponding to a volume of 0.12 pint $(57 \mathrm{~mL}$ ). This was increased up to 1 pint $(473 \mathrm{~mL})$ per watering, as plants grew larger. The volume of water was chosen so that between 5 and $15 \%$ of the nutrient solution leaked from the slabs. 
Plants were supplied with nutrients each time they were watered. The nutrients were supplied in the following minimum concentrations, in parts per million (mg/L): nitrate-N 105, K 140, phosphate-P 40, sulfate-S 50, Ca 130, Mg 35, B 1.4, Fe 3.0, Mn 1.6, Cu 0.4, Zn 0.4, $\mathrm{Mo} 0.1, \mathrm{Cl} 15$. These concentrations were achieved using proportioners (Model A10, Dosmatic, Carrollton TX) that injected one of three nutrient concentrates. One concentrate was a complete fertilizer (3-15-26 tomato and lettuce formula, Hydrogardens, Colorado Springs, $\mathrm{CO}$ ). The other concentrates were calcium nitrate and magnesium sulfate. Sulfuric acid was added to the magnesium sulfate solution to maintain a $\mathrm{pH}$ below 7.5 in the root medium. The nutrient concentrations and the frequency of watering were adjusted according to plant size and light integral, so nutrients were not depleted, and adequate water remained in the root zone. During early fruit growth the nutrient concentrations were about $20 \%$ higher than those stated above, due to high demand by the plants. The concentrations were lowered later in the season to account for more rapid transpiration by the plants. During fruit production, the nutrient solutions for some plants were supplemented to raise the concentrations of nitrogen and/or potassium by about $30 \%$ over the minimum concentrations stated above. The nitrogen supplements included ammonium nitrate in all years except 2000 , and magnesium nitrate in all years except 1999. The potassium supplement was potassium sulfate in 1999 and potassium carbonate in other years.

\section{Cultivars}

Twelve cultivars of greenhouse tomato (Lycopersicon esculentum Mill) were grown in each year. In the first year, the cultivars were chosen to include the most popular cultivars, and cultivars that represented a wide variety of seed sources and fruit characteristics. Cultivars were chosen to represent diverse sources or breeders of tomato, cultivars that were popular 40 years ago or only recently released, cultivars with large or small fruit, and cultivars with or without a uniform ripening characteristic that prevents green shoulder. All cultivars were red when ripe, except Tough Boy was pink. The trial did not include cherry or grape tomatoes. In succeeding years, some cultivars were retained because they did well in previous years, and others were replaced with promising alternatives. Table 1 gives a complete list of cultivars, the seed source, years in trial, and general characteristics. Five cultivars were grown in all four years; Cabernet, Cobra, Dynamo, Match, and Trust. Three cultivars were grown in three years; Buffalo, Jet star, and Mississippi. Six cultivars were grown in two years. The remaining seven cultivars were only grown in one year, either because they had poor yield characteristics, or because they were similar to other cultivars in the trial.

\section{Timing of planting and production}

In 1999, seeds were germinated on 18 March, transplanted to four-inch cubes of rock-wool on 19 April, and set at the final spacing on rock-wool slabs on 20 May. Fruit began to ripen on 4 July and fertilizer treatments commenced on 20 July, and the final harvest was 27 Sept. 1999. There was no shade cloth on the greenhouses. For the 2000 season, seeds were germinated on 30 Dec 1999 , transplanted to 4-inch cubes of rock-wool on $4 \mathrm{Feb} 2000$, and set at the final spacing on rock-wool slabs on 23 Feb. Fruit began to ripen on 1 May and fertilizer treatments commenced on 12 May. A 30\% shade cloth was applied to the houses on 13 June 2000 , and doors were removed to increase ventilation. The final harvest was 15 Aug 2000. In 2001, seeds were germinated on 8 January, transplanted to 4-inch rock-wool pots on 8 February, and set at the final spacing on rock-wool slabs on 7 March 2001. Fertilizer treatments commenced on 1 May and fruit began to ripen about 20 May. On 11 June, doors were removed and $30 \%$ reflective shade cloth was placed over each house. The final harvest was 13 August. In 2002 , seeds were germinated on 30 January, transplanted to 4-inch rock-wool cubes on 26 February, and plants were set at the final spacing on rock-wool slabs on 20 March. Fertilizer treatments commenced on 10 May, and fruit began to ripen on 1 June. Heat was turned off and the doors were removed on 6 June. Shade cloth was not applied in 2002. Picking continued to 26 August.

\section{Experimental design}

There were four rows of 24 plants running along the length of each house. Plant spacing was 2 feet within the row and 2.5 feet between rows, resulting in a density of 5 square feet per plant $\left(2.15\right.$ plants $\left./ \mathrm{m}^{2}\right)$. Each of the four rows within each greenhouse corresponded to one of four different supplemental nutrient treatments. Each row had sub-plots of six different cultivars. Each sub-plot consisted of four plants of one cultivar. Treatment and cultivar locations were randomized within and among greenhouses and from year to year. A complete block of each cultivar by treatment combination required two greenhouses. In 1999, there were only two greenhouses. In other years, there were two complete replicate blocks in four greenhouses. 
Table 1. Name, source, and fruit characteristics of tomato cultivars included in this yield trial.

\begin{tabular}{|c|c|c|c|}
\hline Name & Source & Years in trial & Comments \\
\hline Cabernet & Holmes & 4 & Large fruit, most cracked skin, high total yield \\
\hline Cobra & Vilmorin & 4 & Medium size, green shoulder \\
\hline Dynamo & Sunseeds & 4 & Cluster type, small fruit, most green shoulder \\
\hline Match & DeRuiter & 4 & Popular, uniform ripe, med large fruit \\
\hline Trust & DeRuiter & 4 & Popular, uniform ripe, med large fruit \\
\hline Buffalo & Enza & 3 & Medium size, uniform ripe, good quality \\
\hline Jet Star & Harris & 3 & Large fruit, tends to crack, high total yield \\
\hline Mississippi & Rijk Zwaan & 3 & Med large fruit, resistant to cracking \\
\hline Alexandros & Sunseeds & 2 & Cluster type, small fruit, most BER \\
\hline Cronos & Sunseeds & 2 & Small, uniform ripe, high quality \\
\hline Nicklow 102 & Nicklow & 2 & Largest fruit, uniform ripe, tends to crack \\
\hline Nicklow 21 & Nicklow & 2 & Large fruit, uniform ripe, tends to crack \\
\hline Quest & DeRuiter & 2 & Large fruit, highest market yield, poor germination \\
\hline Tradiro & DeRuiter & 2 & Medium small, uniform ripe, no cracks \\
\hline Capello & DeRuiter & 1 & Large, uniform ripe, tends to crack, high total yield \\
\hline Dalton & Enza & 1 & Cluster type, smallest fruit \\
\hline Parks 656 & Parks & 1 & Medium small, few cracks, green shoulder \\
\hline Pegasus & Sunseeds & 1 & Cluster type, small fruit, green shoulder \\
\hline Perfecto & DeRuiter & 1 & Medium size, uniform ripe, tends to crack \\
\hline Tough Boy & Seedway & 1 & Pink color, small fruit, lowest yield, BER \\
\hline Triton & Enza & 1 & Cluster type, smallest fruit, low yield \\
\hline
\end{tabular}

Analysis of variance was conducted on the total yield accumulated in each year using the general linear model in SYSTAT (Version 10, SPSS Inc., Richmond, CA). All 12 cultivars grown in one year were included in analysis. The cultivars were replicated four to eight times in sub-plots, which corresponded to various nutrient treatments. Tests for the significance of interaction of effects of cultivar and nutrient treatment found no interactions that were consistent from year to year. The results presented here rely on analysis of main effects alone. Main effects were cultivar and nitrogen and potassium supply. As noted elsewhere (Gent 2003), these nutrient treatments generally did not affect yields. The yields reported here are averaged over all nutrient treatments.

Yields varied from year to year during these cultivar trials. Many cultivars were not grown in all four years. In order to compare cultivars that were not grown in the same sequence of years, a year by year correction factor was generated, based on the yields of the five cultivars that were grown in all four years. For these five 
cultivars, the mean value for yield, or a yield-related characteristic was determined in each year, and divided by the average over all years. This year-by-year correction factor was used as a covariate in statistical analysis to determine the significance of differences between cultivars grown in more than one year. It was also used to normalize results for comparisons over the entire four-year trial. 


\section{RESULTS}

Summary over all years

There were significant differences between cultivars in nearly all aspects of fruit yield, fruit size and quality (Table 2), when averaged over the four years of this trial using the method for normalizing the year to year variation as described above. Seven cultivars were only grown in one year. Six of these were grown only in 1999 and one was grown only in 2000 . The values for these cultivars are listed at the bottom of Table 2 . We make no judgment whether the values for cultivars grown in one year are significantly different from other cultivars, because the least significant difference for cultivars only grown in one year was much larger than for those grown in two or more years.

Total yield of each cultivar, averaged over the four years of this trial, varied from 10 to 16 pounds per plant. Yields in kilograms per meter squared are approximately equal to the values in pounds per plant. The ranking for yield and fruit size among cultivars was stable over the four years.

Cabernet was the cultivar with the highest yield over all. However, there were four other cultivars whose yield was indistinguishable from Cabernet. The cultivars from Sunseeds; Dynamo, Alexandros, and Cronos, were among those with the lowest yield. In part, this was because they were cluster tomatoes, and we pruned each truss to 4 or 5 fruit (less than would normally occur on a cluster). The weight fraction of the fruit that was marketable varied from $34 \%$ to $69 \%$. Because of this variation, the ranking in marketable yield was not correlated with that for total yield. Of the cultivars grown in more than one year, Cronos had the highest fraction of marketable fruit, whereas Cabernet had the lowest fraction. Quest had the best yield of marketable fruit, nearly 10 pounds per plant whereas Dynamo and Nicklow 21 had the lowest marketable yield, less than 5 pounds per plant. Nearly all the other cultivars fell into a mid range of 6 to 8 pounds per plant. Ten of the fourteen cultivars grown in more than one year were indistinguishable in their marketable yield.

Average weight per fruit varied greatly. Nicklow 102 had the largest fruit at 7.5 ounces each. The next largest fruit, 6.3 to 6.7 ounces, were picked from Cabernet, Jet Star, Nicklow 21 and Quest. There were other distinct size classes, all the way down to that of the Sunseed varieties, which had the smallest fruit at about 3 ounces per fruit. A major problem with large-fruited cultivars was cracks in the skin of the fruit. Cabemet had Table 2. Summary of yield characteristics of each tomato cultivar grown in any of four years of a greenhouse trial using rockwool substrate. more fruit with cracked skin, on a number basis, than any other cultivar, and this was the main reason why it had a low marketable yield. Nicklow 21 and 102, and Jet Star were cultivars for which about a third of the fruit had cracked skin. In contrast, only about $10 \%$ of the smallfruited varieties had cracks in the skin. Quest did not follow this trend, in that it had large fruit but a relatively low fraction with cracked skin. Mississippi shared the same behavior, although it had smaller fruit than Quest.

Green shoulder or uneven ripening was the other common defect of fruit. A quarter of the fruit picked from Dynamo had this defect. Cabernet, Cobra, and Alexandros were other varieties in which more than $10 \%$ of the fruit had green shoulders. Because of strict judging criteria, many cultivars which had the uniform-ripening gene, and thus should have no green shoulder, were evaluated as having between $3 \%$ and $6 \%$ green shoulder. There was a relatively low frequency of blossom end rot with our cultural practices. Alexandros and Jet Star were substantially different than the other varieties, in that about $10 \%$ of their fruit had blossom end rot. For many of the other cultivars, only about $2 \%$ of the fruit had this defect.

The fraction of dry matter is related to the soluble solids content of the fruit. For nearly all cultivars, this fraction ranged from $5.5 \%$ to $5.8 \%$. Some Sunseed cultivars had an unusually high fraction of dry matter; $6.9 \%$ for Alexandros, and 6\% or more for Cronos and Dynamo. Match and Trust had the lowest dry matter content. The cultivars with highest or lowest dry matter were the same from year to year. 


\begin{tabular}{lcccccccc}
\hline & $\begin{array}{c}\text { Total } \\
\text { pounds/plant }\end{array}$ & $\begin{array}{c}\text { Market } \\
\text { Name }\end{array}$ & $\begin{array}{c}\text { Marketable } \\
\text { fraction } \\
\text { weight\% }\end{array}$ & $\begin{array}{c}\text { Fruit } \\
\text { size } \\
\text { ounce }\end{array}$ & $\begin{array}{c}\text { Pracked } \\
\text { skin }\end{array}$ & $\begin{array}{c}\text { Green } \\
\text { shoulder }\end{array}$ & $\begin{array}{c}\text { Blossom } \\
\text { end rot }\end{array}$ & $\begin{array}{c}\text { Dryatter } \\
\text { percent }\end{array}$ \\
\hline Alexandros & $10.4 \mathrm{c}$ & $5.8 \mathrm{bc}$ & $54 \mathrm{~b}$ & $2.9 \mathrm{~g}$ & $11 \mathrm{~d}$ & $14 \mathrm{bc}$ & $11.1 \mathrm{a}$ & $6.9 \mathrm{a}$ \\
Buffalo & $13.0 \mathrm{~b}$ & $7.8 \mathrm{~b}$ & $59 \mathrm{ab}$ & $5.4 \mathrm{~d}$ & $24 \mathrm{c}$ & $3 \mathrm{~d}$ & $1.5 \mathrm{c}$ & $5.8 \mathrm{bc}$ \\
Cabernet & $16.1 \mathrm{a}$ & $5.6 \mathrm{c}$ & $34 \mathrm{c}$ & $6.7 \mathrm{~b}$ & $44 \mathrm{a}$ & $16 \mathrm{~b}$ & $3.7 \mathrm{~b}$ & $5.7 \mathrm{bc}$ \\
Cobra & $13.3 \mathrm{~b}$ & $6.2 \mathrm{bc}$ & $46 \mathrm{bc}$ & $5.2 \mathrm{~d}$ & $25 \mathrm{c}$ & $14 \mathrm{bc}$ & $1.5 \mathrm{~b}$ & $5.8 \mathrm{bc}$ \\
Cronos & $10.0 \mathrm{c}$ & $7.1 \mathrm{~b}$ & $69 \mathrm{a}$ & $3.2 \mathrm{~g}$ & $7 \mathrm{~d}$ & $3 \mathrm{~d}$ & $1.9 \mathrm{bc}$ & $6.3 \mathrm{ab}$ \\
Dynamo & $10.3 \mathrm{c}$ & $4.7 \mathrm{c}$ & $44 \mathrm{bc}$ & $3.0 \mathrm{~g}$ & $10 \mathrm{~d}$ & $25 \mathrm{a}$ & $0.9 \mathrm{c}$ & $6.0 \mathrm{bc}$ \\
Jet Star & $15.5 \mathrm{a}$ & $6.9 \mathrm{~b}$ & $44 \mathrm{bc}$ & $6.3 \mathrm{bc}$ & $33 \mathrm{~b}$ & $2 \mathrm{~d}$ & $8.8 \mathrm{a}$ & $5.7 \mathrm{bc}$ \\
Match & $14.4 \mathrm{ab}$ & $7.6 \mathrm{~b}$ & $52 \mathrm{~b}$ & $6.1 \mathrm{c}$ & $29 \mathrm{bc}$ & $4 \mathrm{~d}$ & $1.9 \mathrm{bc}$ & $5.5 \mathrm{c}$ \\
Mississippi & $13.9 \mathrm{~b}$ & $7.3 \mathrm{~b}$ & $52 \mathrm{~b}$ & $6.0 \mathrm{c}$ & $22 \mathrm{c}$ & $9 \mathrm{c}$ & $1.9 \mathrm{bc}$ & $5.7 \mathrm{bc}$ \\
Nicklow 102 & $14.7 \mathrm{ab}$ & $6.6 \mathrm{bc}$ & $44 \mathrm{bc}$ & $7.5 \mathrm{a}$ & $35 \mathrm{~b}$ & $3 \mathrm{~d}$ & $3.4 \mathrm{~b}$ & $5.6 \mathrm{c}$ \\
Nicklow 21 & $11.4 \mathrm{bc}$ & $4.8 \mathrm{c}$ & $41 \mathrm{bc}$ & $6.3 \mathrm{bc}$ & $34 \mathrm{~b}$ & $6 \mathrm{~b}$ & $2.3 \mathrm{bc}$ & $5.9 \mathrm{bc}$ \\
Quest & $14.7 \mathrm{ab}$ & $9.8 \mathrm{a}$ & $66 \mathrm{a}$ & $6.7 \mathrm{~b}$ & $22 \mathrm{c}$ & $3 \mathrm{~d}$ & $1.1 \mathrm{c}$ & $5.6 \mathrm{c}$ \\
Tradiro & $11.4 \mathrm{bc}$ & $6.7 \mathrm{bc}$ & $58 \mathrm{ab}$ & $4.0 \mathrm{e}$ & $12 \mathrm{~d}$ & $9 \mathrm{~cd}$ & $3.8 \mathrm{~b}$ & $5.6 \mathrm{c}$ \\
Trust & $14.2 \mathrm{ab}$ & $7.4 \mathrm{~b}$ & $51 \mathrm{~b}$ & $6.1 \mathrm{c}$ & $25 \mathrm{c}$ & $6 \mathrm{~cd}$ & $2.1 \mathrm{bc}$ & $5.5 \mathrm{c}$ \\
L.s.d. & 1.8 & 1.5 & 10 & 0.2 & 8 & 5 & 1.6 & 0.5
\end{tabular}

Cultivars grown in only one year

$\begin{array}{lcccccccc}\text { Capello } & 15.0 & 5.3 & 35 & 6.0 & 38 & 3 & 0.7 & 5.5 \\ \text { Dalton } & 7.1 & 5.2 & 73 & 2.2 & 4 & 3 & 8.2 & 6.0 \\ \text { Parks } 656 & 13.0 & 6.9 & 52 & 4.4 & 17 & 18 & 3.8 & 6.3 \\ \text { Pegasus } & 9.4 & 4.4 & 46 & 3.5 & 18 & 17 & 2.5 & 7.1 \\ \text { Perfecto } & 14.1 & 4.0 & 27 & 5.3 & 38 & 3 & 1.6 & 6.1 \\ \text { Tough Boy } & 6.1 & 2.6 & 43 & 3.5 & 25 & 8 & 5.3 & 7.2 \\ \text { Triton } & 6.3 & 4.5 & 69 & 2.2 & 13 & 1 & 4.3 & 6.7\end{array}$

Values in the same column followed by different letters are significantly different at $\mathrm{P}<0.05$. L.s.d. Least significant difference at $\mathrm{P}<0.05$. 
The timing of fruit production varied among years (Figure 1). In 1999, the planting was late, the summer was hot and sunny, and no shade cloth was applied on the greenhouses. The tomatoes did not begin to ripen until mid-July. The rate of production was slower than in other years. The rate of production was slowed further by decreasing light intensity in September. The environment in 2000 differed from that in 1999. Spring was warm and sunny and summer was cool and wet. A $30 \%$ shade cloth was applied to the houses and doors were removed to increase ventilation. Fruit began to ripen earlier in 2000 than in any other year. However the rate of early production was not as rapid as in later years. Spring was cool and snowy in 2001 , but summer was warm. Shade cloth was applied in 2001. The final yield in 2001 was similar to that in 2000 , but the rate of production differed throughout the season. There was negligible yield in May but the rate of production in June was faster than in 2000 . In 2002, early spring was cool and cloudy, but the summer had an average temperature. Early yield was delayed by later germination and transplanting than in 2000 or 2001 , and by an early-season problem with ethylene poisoning, which caused the first flowers of many plants to abort. However, the rate of production in July and August was faster than in any other year.

The highest yields and fruit sizes were achieved in 2002 (Table 3 ) when averaged over all cultivars grown in one year. In part, this was because no shade was used and picking was extended to the end of August in 2002. In part, it was because the highest-yielding cultivars from previous years were grown in 2002 . The percentage of fruit that was marketable was greater than in 1999, the other year in which tomatoes were produced in a greenhouse without shade, but the market percentage was less than in 2000 or 2001 , when plants were grown under $30 \%$ shade cloth during fruit production. The percentage of fruit with cracked skin in 2002 was two times that in 2000 , but less than that in 1999, in part due to the superiority of the cultivars selected in 2002 . The incidences of green shoulder and blossom end rot were higher in 2002, than in years when the greenhouses were shaded, but less than in 1999. The fraction of dry matter in the fruit was lowest in 2002, and thus did not seem to be related to shading the greenhouse.

In 2001, the average weight per fruit, 5.8 ounces, was much larger than the fruit picked in 1999 and 2000 (Table 4). The cultivars that were grown in every year showed this trend from year to year in fruit size, with fruit about one ounce larger in 2001 than in 2000 . Because of the difference in fruit size, the incidence of fruit with cracked skin was greater in 2001 than 2000, 21 and 15\%, respectively. Nevertheless, this was a much lower incidence of fruit with cracked skin than in 1999. The fraction of fruit with green shoulder or blossom end rot was only $5 \%$ and $1 \%$, respectively, in both 2000 and 2001.

\section{Difference among cultivars within years}

In 1999, the highest-yielding cultivars only produced 11 pounds per plant. Cobra, Trust, and Buffalo had the highest marketable yield. Fruit size of the cultivars fell into two classes, those with fruit weighing more than 4.8 ounces and those less than 3 ounces. The highest incidence of fruit with cracked skin was observed in 1999. The cultivars Cabernet and Match had the most cracked skin. The highest incidence of green shoulder also occurred in 1999. Blossom end rot was worse than in other years, particularly for Pegasus which had $26 \%$ blossom end rot. Fruit dry matter as a fraction of fresh weight was higher than other years. Pegasus and Tough Boy had more than $7 \%$ dry matter, compared to less than $6 \%$ dry matter in most cultivars.

Cabernet had the highest yield in 2000 , and Match and Jet Star were the next highest yielding cultivars. Cobra, Dynamo, Alexandros and Nicklow 21 had the lowest yield. Cabernet had the largest fruit; Dynamo and Alexandros had the smallest. Alexandros had the highest dry matter overall. Trust and Nicklow 21 had the lowest dry matter. In general, acidity, and composition of cations such as $\mathrm{K}, \mathrm{Ca}$ and $\mathrm{Mg}$ in the fruit on a fresh weight basis, scaled according to dry matter as a fraction of fresh weight (data not shown).

Cabernet had the highest yield in 2001, but it also had the most cracked skin and lowest marketable percentage (Table 6). Cronos had the highest marketable percentage but small fruit. Nicklow 102 and 21, Quest and Cabernet had the largest fruit. Cobra was intermediate in fruit size. Dynamo and Alexandros had the lowest yield and the smallest fruit. Quest had the highest marketable yield, but it was not significantly greater than Mississippi, Match, Trust or Nicklow 102. Alexandros and Dynamo had an incidence of green shoulder greater than $10 \%$. Alexandros had very high dry matter, $7.4 \%$. All other cultivars, except Cronos, had less than $6 \%$ dry matter. Alexandros and Jet Star had the most blossom and rot, but the incidence was $5 \%$ or less. 


\section{Yield over time}

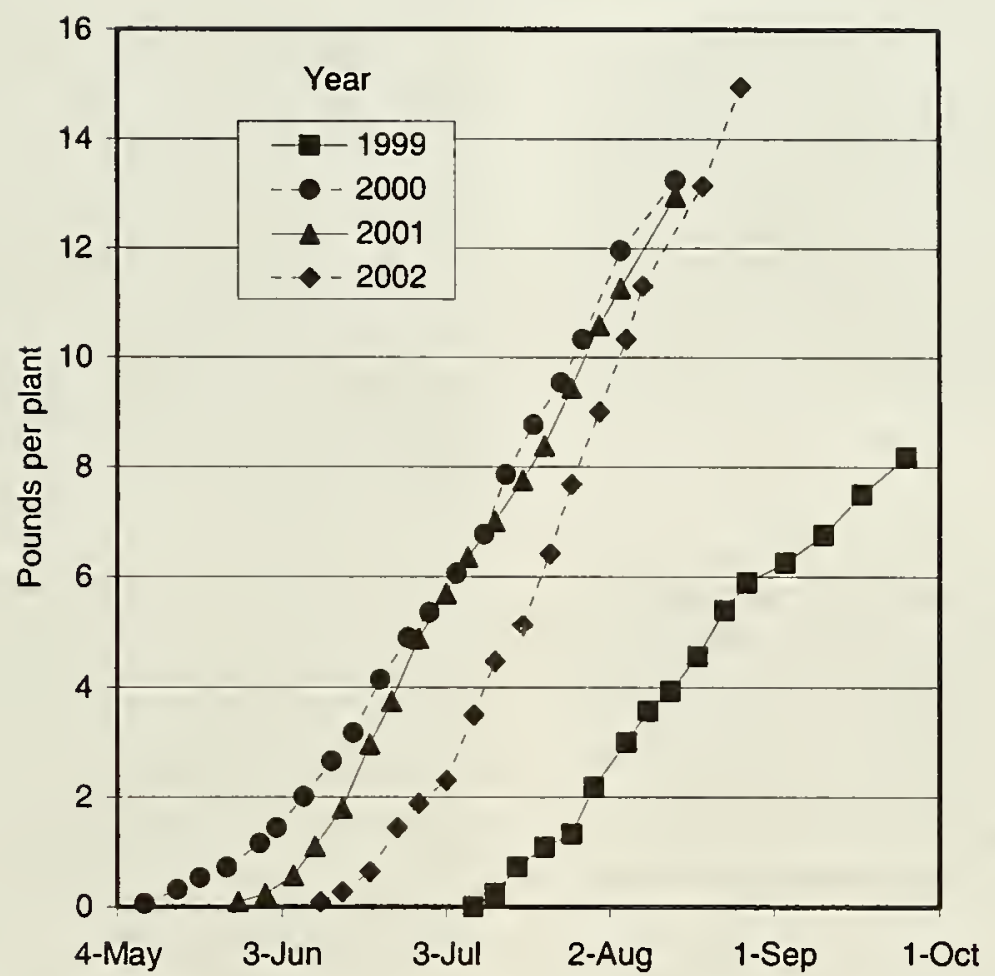

Figure 1. The accumulation of yield as a function of time in four years. The symbols for each year represent the yield averaged over all cultivars grown in that year.

Table 3. Year to year variation in yield characteristics averaged over all tomato cultivars grown in each year in a greenhouse trial using rock-wool substrate.

\begin{tabular}{lcccccccc}
\hline Year & $\begin{array}{c}\text { Total } \\
\text { pounds/plant }\end{array}$ & $\begin{array}{c}\text { Yield } \\
\text { parket }\end{array}$ & $\begin{array}{c}\text { Marketable } \\
\text { fraction } \\
\text { weight\% }\end{array}$ & $\begin{array}{c}\text { Fruit } \\
\text { size } \\
\text { ounce }\end{array}$ & $\begin{array}{c}\text { Pracked } \\
\text { skin }\end{array}$ & $\begin{array}{c}\text { Green total number } \\
\text { shoulder }\end{array}$ & $\begin{array}{c}\text { Blossom } \\
\text { end rot }\end{array}$ & $\begin{array}{c}\text { Dry } \\
\text { matter } \\
\text { percent }\end{array}$ \\
\hline 1999 & 8.7 & 2.7 & 32 & 4.2 & 40 & 13 & 9 & 6.3 \\
2000 & 14.1 & 8.1 & 58 & 4.5 & 15 & 5 & 1 & 5.9 \\
2001 & 13.7 & 7.6 & 56 & 5.8 & 21 & 5 & 1 & 5.8 \\
2002 & 15.7 & 8.1 & 44 & 6.2 & 30 & 14 & 4 & 5.7
\end{tabular}

In 2002, Dynamo, Tradiro and Cronos yielded less than the highest yielding cultivars. Cronos, Quest and Buffalo had the highest marketable percentage. Quest had the highest marketable yield, but it was not significantly better than five other cultivars. Dynamo had the lowest marketable yield. Nicklow 102 had the largest fruit, while Dynamo and Cronos had the smallest.

Cabernet and Nicklow 102 had the most cracked skin.
Quest was distinguished by having relatively large fruit but a low incidence of cracked skin. Dynamo and Cabernet had the most green shoulder. Jet Star and Cabernet had the most blossom end rot. The cultivars did not differ significantly in the fraction of dry matter in fruit. 


\section{Effects of nutrient treatments}

The nutrient treatments only had a significant effect on yield in 1999. The ammonium nitrate supplement decreased yield from 8.9 to 7.5 pounds per plant and decreased fruit size by $1 / 2$ ounce (Gent 2003). This supplement did effect fruit quality, when effects were analyzed over all years for the 14 cultivars that were grown in more than one year. The ammonium nitrate supplement decreased fruit size, which also slightly decreased the incidence of cracked skin. The most significant effect of the ammonium nitrate supplement was a 3-fold increase in blossom end rot. The treatments had marginal effects on fruit composition.

\section{DISCUSSION}

In general, the ranking among cultivars of total yield, market yield, and fruit size remained the same from year to year in this trial. Each of these characteristics did vary from year to year when averaged over cultivars, most likely due to various environmental factors. The relative independence of effects of genotype and environment suggests the same ranking should be obtained if these cultivars were grown in other types of greenhouses, or in other regions.

Quest had the highest yield of marketable fruit in this trial. This cultivar is currently the most popular for production in Belgium and France (DeRuiter 2002). This cultivar was likely bred for rock-wool culture, as it produced high quality fruit under this method of cultivation. Match, Trust, and Buffalo were cultivars with slightly lower marketable yields. These cultivars are currently the most popular among commercial greenhouse vegetable growers in the northeast US. Their marketable yields were similar to Mississippi, a cultivar with similar sized fruit, and Cronos with small fruit. All the cultivars listed above have the uniform ripening gene and had a low incidence of green shoulder.

There were other cultivars in the present trial that produced larger fruit than Quest, such as Cabernet, Jet Star, and Nicklow 102. These cultivars had high total yields, but marketable yield was lowered by a substantial number of fruit with cracked skin. Cronos was the only cultivar among the cluster types that had marketable yield equal to Trust. Cronos had a high marketable yield because it did not suffer from green shoulder, or fruit too small to be marketable, namely those less than 2 ounces. Both of these defects were common in the other cluster types in this trial.

Trust is the most widely recommended cultivar in the US. It appears in many of the greenhouse cultivar trials that have been published in recent years. Trust yielded as well as several other beefsteak cultivars in a trial in Nova Scotia, and it produced among the largest fruit, (Toms and Haskins 1996). Tradiro, a cluster type, yielded about $10 \%$ less than the beefsteak types in that trial. The Nova Scotia trial was conducted during a similar period of the year as the present trial, production was from 17 May through 5 August. However, the trial in Nova Scotia resulted in yields about twice those presented here, and a relatively low cull percentage of only 8 to $13 \%$ non-marketable fruit. In a trial in Florida, six beefsteak types were harvested from mid-December through March. Yields ranged from 18 to $27 \mathrm{lb}$ per plant. Mississippi was the highest yielding, and Quest was among the lowest yielding cultivars in that trial (Hochmuth et al 2000). The yield of Trust was only slightly less than that of Mississippi. Fruit size was about $7 \mathrm{oz}$ for all these cultivars. A trial of cluster types was conducted at the same site in Florida. Tradiro yielded least of all the cluster types in this trial, 12 pounds per plant, and fruit size was $4 \mathrm{oz}$ (Hochmuth et al 2000). In a trial conducted in winter and spring in Arizona, Trust and Quest had similar yields and fruit size (Rorabaugh and Jensen 2001). These yields where in the middle of the range of all cultivars tested in the Arizona trial; the range was from 14.3 to $22.1 \mathrm{~kg}$ per meter squared. In a taste test, Trust and Quest ranked highest among the cultivars grown in the Arizona trial.

Production guides available in several states give recommendations and production characteristics for various tomato cultivars. The expected yield and fruit size for Trust in Ohio was $8.2 \mathrm{lb}$ per plant and $5.8 \mathrm{oz}$ per fruit (Precheur 2003). Similar yields were expected for Cobra and Cappelo, two other cultivars in the current trial. In Oregon, Trust was among the best adapted cultivars west of the Cascades, and Perfecto and Capello were among the best adapted east of the Cascade Mountains (Oregon 2002). Expected fruit size for these cultivars was 6.5 to $7.5 \mathrm{oz}$ per fruit. Trust and Match performed well in experimental trials in Louisiana, as well as older cultivars such as Jumbo and Tropic. Trust produced 6 to $8 \mathrm{oz}$ fruit while average fruit size for Jumbo and Tropic were 8 to $9 \mathrm{oz}$ (Koske et al 1998).

There is considerable variation in yield among these various trials and reports. In part this may be explained by the duration of production. For instance, the production period in the current trial was about three months. The trial in Florida lasted four months, and yields were at least $25 \%$ higher in that trial. The trial in Arizona lasted for 30 weeks and yields of marketable fruit were two to three times those reported here. A production of 20 to $25 \mathrm{lb}$ per plant per year was expected in a twocrop system in Oregon, with one crop picked from August through December, and a second crop picked through 
June. Thus, each crop would yield about $12 \mathrm{lb}$ per plant, as much as in the current trial.

The fruit sizes reported here were less than reported elsewhere. In part, this was because the plants produced small fruit in the first two years of the trial. For instance, Trust had a fruit size of 5.7 and $5.3 \mathrm{oz}$ per fruit, in 1999 and 2000, respectively. The fruit size increased to 6.5 and $6.8 \mathrm{oz}$ in 2001 and 2002 . The latter is only slightly less than 7.2 and $7.1 \mathrm{oz}$ reported for this cultivar in the Florida and Arizona trials. However, it is substantially less than the $8 \mathrm{oz}$ reported in the Nova Scotia trial. The fruit size obtained for Trust was similar to that expected in Ohio in the first two years of the current trial, and similar to that expected in Oregon in the last two years of the current trial.

The yield of Buffalo in this trial could be compared to yields from an earlier trial conducted in the same greenhouses in 1994 and 1995 (Gent and Ma 1998). In the earlier trial, seedlings were transplanted in either early- or late-March into troughs containing a peat-lite mix. Buffalo yielded $13.7 \mathrm{lb}$ and had a fruit size of $4.8 \mathrm{oz}$ when planted early, and yielded $11.7 \mathrm{lb}$ and a fruit size of $5.3 \mathrm{oz}$ when planted in late-March. When grown in rockwool in the current study, the yield of Buffalo was similar to that in the previous trial when planted in 2000 , but both the yield and fruit size were considerably greater when planted in 2002. The yield in 1999 was a lot less than when grown earlier in peat-lite mix.

The yields and rates of production achieved in the various years of this trial give some suggestion as to the optimum conditions for planting and production in Connecticut. The worst yields came in 1999, a year in which the plants were started late and production was continued into September. Clearly, this was not the best timing for production. In 2000, the year with the earliest planting, the fruit ripened earliest, but the rate of production during the first month or so was less than in other years. Thus, it was more difficult to achieve a constant rate of production by starting plants early. We achieved a more constant rate of production by transplanting in early March, so that fruit commenced to ripen in late May. The early-March yield was superior to late-March yield in the earlier trial, when both plantings were picked until the same end date. A late-March planting was superior to early-March planting in regards to fruit size. However delaying transplant until May results in poor yield and fruit quality. In the current trial, all plantings were picked for an approximately equal duration, and yields increased in each year of the current trial. At least by the end of the present trials, the cultural conditions were such that Buffalo yielded more and larger fruit when grown in rockwool than it yielded in earlier trials when grown in peat-lite mix. Thus, there did not seem to be any penalty, and there may be a benefit to growing plants in rock-wool as opposed to other media.

Shade had an effect on the yield and quality of the tomato fruit. We achieved the most rapid rate of fruit production in 2002 when no shade was applied to the greenhouse. However, fruit quality was diminished primarily due to more cracking of the fruit, compared to 2000 and 2001, when plants were grown under $30 \%$ shade cloth. In fact, marketable yields were greatest in 2000 and 2001, even though total yield was not. It is possible that an intermediate shade condition between 0 and $30 \%$ shade would optimize the yield of marketable tomatoes when grown in greenhouses in Connecticut.

It should be noted that some aspects of rockwool culture differ from that in peat-lite mix. Rockwool should never be allowed to run dry, because this increases electrical conductivity or concentration of nutrients in the remaining solution to the point where it has deleterious effects on fruit size and other aspects of plant function. In peat-lite medium, the plants suffer little harm until all the water is gone and they begin to wilt. The solution in rockwool medium tends towards a basic $\mathrm{pH}$ if the plants are fed with nitrate as the nitrogen source. This effect is compounded by the high $\mathrm{pH}$ found in rock-wool before it is used. Thus, phosphoric, sulfuric or nitric acid must be added to the nutrient solution to bring the $\mathrm{pH}$ down to the recommended level of 5.6 to 6.6 . Because of the natural acidity of peat, this addition of acid is not necessary when peat is used as a root medium.

In summary, the most popular cultivars for greenhouse tomato production at present were among the best, in terms of marketable yield in this yield trial. Buffalo, Match and Trust were only exceeded in marketable yield by Quest. Cultivars have been developed more recently that exceed the yield of Quest, when compared in trials in other climates (Rorabaugh and Jensen 2001, Deruiter 2002). Such cultivars will be included in future greenhouse tomato trials in Connecticut. The cultivars with the highest marketable yield did not have the largest fruit or the greatest total yield. Other cultivars may be more suitable for particularly production or retail conditions. The various characteristics listed in the tables should help to select greenhouse tomato cultivars that may be more suitable for a particular niche.

\section{ACKNOWLEDGEMENT}

I thank Mr. Michael Short for technical assistance. The New England Vegetable and Berry Growers Association provided financial support. 


\section{REFERENCE LIST}

Aldrich R.A., and Bartok, J.W. 1994. Greenhouse Engineering. Northeast Regional Agricultural Engineering Service, Ithaca, NY. 212 pages.

Anderson R. 1996. Greenhouse tomato production practices. University of Kentucky, Dept. of Horticulture Pub. http://www.uky.edu/Agriculture/Horticulture/anders on/gh tom.htm

Blom, T., Fisher C., Ingratta F., Jarvis W., Papadopoulos T., Potter J., Smith I., Straver W., and Tiessen. H. 1989. Growing greenhouse vegetables. Pub. 526. Ontario Ministry of Agriculture and Food, Toronto, Ontario, Canada.

De Ruiter. 2002. Tomato beefsteak varieties. De Ruiter Seeds, Inc., Columbus, $\mathrm{OH}$

http://www.deruiterusa.com/products/Tomato/Beef/ beef.hrml

Ells, J.E., Butler J.D., Hanan J.J., and Holley W.D. 1991. Hydroponics - growing plants without soil. Cooperative Extension Service, Colorado State Univ. Factsheet, 7.616.2. 8 pages

Dickerson G.W. 1998. Greenhouse Vegetable Production. College of Agriculture and Home Economics, New Mexico State University, Circular 556. 12 pages. http://cahe.nmsu.edu/pubs/ circulars/circ556.html

Donnell, M. 2001. Hydroponics resource list. O. A. R. D. C., Dept of Food, Agric. and Biol. Eng., Ohio State University. http://www.oardc.ohiostate.edu/hydroponics/Links/links.htm

Gent, M.P.N., Ma Y-Z. 1998. Diurnal temperature variation of the root and shoot affects yield of greenhouse tomato. HortScience 33:47-51.

Gent, M.P.N. 2003. Effect of nitrogen and potassium supplements on yield and quality of greenhouse tomato. Submitted to Acta Horticulturae. 8 pages

Hanan, J.J., Holley W.D., and Goldsberry K.L. 1978. Greenhouse Management. Springer Verlag, New York, NY. 530 pages.

Hochmuth, R.C., Davis L.L., Tillman N. 2000. Evaluation of greenhouse beefsteak and cluster tomato varieties for north Florida, 1999-2000 season. University of Florida, North Florida Research and Education
Center Suwannee Valley, Res. Report 2000-02. 5 pages

Jensen M. and Rorabaugh P. 2001. Growing tomatoes hydroponically. University of Arizona Controlled Environment Agricultural Center. http://ag.arizona.edu/hydroponictomatoes

Koske T.J., Pollet D., Ring D., Hinson R., Sanderlin R., Whitam K. 1998. Greenhouse tomatoes. Louisiana State University Agricultural Center, Pub. 1808. 24 pages. http://www.Isuagcenter.com/Communications/pdfs bak/publ808.pdf

Oregon. 2002. Greenhouse tomato. Commercial Vegetable Production Guide, Oregon State University North Willamette Research \& Extension Center. http://oregonstate.edu/Dept/NWREC/tomatogh.html

Peet M.M. 1999. Greenhouse vegetable list of references., North Carolina State University Horticultural Information Leaflets, HIL-32-A. 15 Pages. http://www.ces.ncsu.edu/depts/hort/hil/pdf/hil-32a.pdf

Precheur R.J. ed. 2003. Greenhouse tomatoes. Ohio Vegetable Production Guide, Ohio Sate University Extension Bulletin 672-03. http://ohioline.osu.edu/b672/greenhouse tomatoes.h tml

Resh, H.M. 1995. Hydroponic food production: a definitive guidebook of soilless food-growing methods. 5th ed.Woodridge Press Pub. Co. Santa Barbara, CA. 527 pages.

Rorabaugh P., Jensen M. 2001. A trial to test heat tolerant tomato varieties for use in desert climates. University of Arizona, College of Agriculture and Life Sciences, Controlled Environment Agricultural Center Paper \#R-125933-15-01. http://ag.arizona.edu/ceac/research/archive/heattrial. $\underline{\mathrm{htm}}$

Snyder R.G. 2001. Greenhouse tomato handbook. Mississippi State University Publication 1828, 340 pages. http://msucares.com/pubs/publications/pub1828.htm

Toms B., Haskins A. 1996. Greenhouse Tomato Cultivar Trial 1996. Nova Scotia Department of Agriculture and Marketing, Horticulture Project summaries 1996, 1 page. 
http://www.gov.ns.ca/nsaf/elibrary/archive/projsum/

96/ahtomato.htm

Wittwer S.H. and Honma S. 1979. Greenhouse tomatoes, lettuce and cucumber. Michigan State University Press, East Lansing, MI, 225 pages. 


\footnotetext{
The Connecticut Agricultural Experiment Station (CAES) prohibits discrimination in all its programs and activities on the basis of race, color, ancestry, national origin, sex, religious creed, age, political beliefs, sexual orientation, criminal conviction record, genetic information, learning disability, present or past history of mental disorder, mental retardation or physical disability including but not limited to blindness, or marital or family status. To file a complaint of discrimination, write Director, The Connecticut Agricultural Experiment Station, P.O. Box 1106, New Haven, CT 06504, or call (203) 974-8440. CAES is an equal opportunity provider and employer. Persons with disabilities who require alternate means of communication of program information should contact the Chief of Services at (203) 974-8442 (voice); (203) 974-8502 (FAX); or Michael.Last@po.state.ct.us (E-mail).
} 
